Nunt. Antiquus, Belo Horizonte, v. 14, n. 2, p. 125-153, 2018

\title{
Figurações poéticas da vida rural nas Geórgicas
}

\section{Poetic Figurations of Rural Life in the Georgics}

\author{
Matheus Trevizam \\ Universidade Federal de Minas Gerais (UFMG), Belo Horizonte, Minas Gerais / Brasil \\ mattrevi2017@gmail.com
}

Resumo: Neste artigo, desejamos mostrar que as Geórgicas de Virgílio, embora apresentem evidentes pontos de contato com as práticas rurais em Roma Antiga, não podem ser realmente consideradas um documento sobre a ruralidade romana. Alguns elementos que nos permitem pensar nessa obra, sobretudo, como produto de criação poética são a falta de detalhamento e a "seletividade" dos tópicos que se incorporam à abordagem técnica do "professor". Além disso, análises feitas por Philip Thibodeau (2011) provam que, embora os cativos não sejam de todo omitidos no âmbito da preceituação de Virgílio, a eliminação do uilicus - administrador rural - permite ao público interagir com o texto de maneira mais decorosa, pondo-se como discipulus na posição de um agricola ("cultivador livre"), não de algum tipo de escravo.

Palavras-chave: poesia didática; agricultura; ficção; poesia; Virgílio.

Abstract: In this article we intend to show that Virgil's Georgics, despite presenting obvious points of contact with some rural practices existing in ancient Rome, should not be taken as a strict document on Roman rurality. Some elements allow us to consider it mainly as a product of poetic creation more than as a pure expression of reality, such as the lack of details and the "selectivity" found in some of the topics incorporated to the teacher's technical approach. In addition to this, some reviews conducted by Philip Thibodeau (2011) show that even though the slaves were not completely overlooked under Virgil's precepts, the elimination of the uilicus - rural administrator - allowed the public to interact with the text in a more decent way, making each one of them to become a sort of discipulus in the position of an agricola ("free cultivator") instead of some kind of slave.

Keywords: didactic poetry; agriculture; fiction; poetry; Virgil. 


\section{Introdução}

Diante de um poema didático como as Geórgicas virgilianas, deparamos um artefato literário complexo. De um lado, então, essa obra, ao longo de seus quatro livros, apresenta-nos o que parece corresponder a uma espécie de panorama dos afazeres rurais na Itália antiga, com seu conjunto de preceitos em nexo, respectivamente, com os campos de cereais (livro I), a arboricultura (livro II), a pecuária (livro III) e a apicultura (livro IV). Nisso ainda se incluem detalhes capazes de conceder mínima credibilidade ao papel "instrutivo" do magister didático do texto, como certas operações da vida camponesa indispensáveis à produção agropecuária. ${ }^{1}$ Também atribuímos ao fundo "factual" das Geórgicas a presença de personagens e espaços tipicamente associáveis à rotina agrícola dos romanos, a exemplo do mestre de rebanho ${ }^{2}$ e da eira de debulha de cereais:

${ }^{1}$ VIRGÍLIO, Geórgicas I, 79-81: Sed tamen alternis facilis labor; arida tantum/ ne saturare fimo pingui pudeat sola, neuel effetos cinerem immundum iactare per agros. - "Entretanto, o esforço é fácil com alternância; apenas não/ seja fastidioso impregnar a terra com o rico estrume nem/ lançar por campos exaustos a cinza imunda" (grifos nossos). Veja-se também Catão, De agri cultura XXIX: Stercus diuidito sic. Partem dimidiam in segetem, ubi pabulum seras, et si ibi olea erit, simul ablaqueato stercusque addito: postea pabulum serito. Partem quartam circum oleas ablaqueatas, quom maxime opus erit, addito terraque stercus operito. - "Reparte o esterco assim: leva metade para a lavoura quando plantares a forragem e, se lá houver oliveiras, ao mesmo tempo ablaqueia e põe esterco; em seguida, planta a forragem. Na época de maior necessidade, põe a quarta parte em torno das oliveiras ablaqueadas e encobre o esterco com terra". Todas as traduções, salvo avisos, são do autor do artigo.

${ }^{2}$ VIRGÍLIO, Geórgicas II, 529-531: Te, libans, Lenaee, uocat, pecorisque magistris/ uelocis iaculi certamina ponit in ulmo,/ corporaque agresti nudant praedura palaestra. - "A ti, fazendo libações, ó Leneu, ele invoca e, para o mestre de rebanho,/ dispõe no olmo os certames do dardo veloz,/ despem-se corpos resistentes no ginásio agreste" (grifos nossos). Magister pecoris correspondia, como explica R. F. Thomas em nota ad locum (VIRGIL, 1994, p. 261), ao "chefe dos pastores" ("chief herdsman"), ou seja, àquele no comando dos assuntos pecuários em uma propriedade rural na Roma Antiga. 


\begin{abstract}
Area cum primis ingenti aequanda cylindro et uertenda manu et creta solidanda tenaci, ne subeant herbae neu puluere uicta fatiscat, tum uariae inludant pestes: saepe exiguus mus sub terris posuitque domos atque horrea fecit, aut oculis capti fodere cubilia talpae, inuentusque cauis bufo et quae plurima terrae monstra ferunt, populatque ingentem farris aceruom curculio atque inopi metuens formica senectae.
\end{abstract}

(VIRGÍLIO, Geórgicas I, 178-186) ${ }^{3}$

No excerto acima, em que pesem efeitos compositivos atinentes, sobretudo, a intensificar pela enumeração de males o caráter inconstante e perigoso dos trabalhos agrícolas nos tempos coevos/Era de Júpiter, ${ }^{4}$ é inegável que se oferecem didaticamente alguns conselhos elementares com vistas a "direcionar" o seguro estabelecimento do espaço rústico em pauta. Ele necessita, assim, "ser nivelado" - aequanda, v. 178 -, "revirado à mão" - uertenda manu, v. 179 - e "solidificado com greda tenaz" - creta solidanda tenaci, v. 179 -, vindo a dar-se, no contexto, que se trate de medidas destinadas a precauções diante de vários agentes "invasivos" da eira, como as "ervas" - herbae, v. 180 -, o "pó" - puluere,

3 "Primeiro, a eira deve ser nivelada com enorme cilindro,/ revirada à mão e solidificada com greda tenaz,/ para não se insinuarem as ervas nem rachar vencida pelo pó,/ e então escarnecerem várias pestes: amiúde, pequeno rato/ sob as terras estabeleceu morada e fez celeiros,/ ou escavaram suas câmaras toupeiras sem visão,/ em covas se encontraram o sapo e abundantes monstros que/ as terras produzem, pilham enorme monte de trigo/ o gorgulho e a formiga a temer velhice pobre".

${ }^{4} \mathrm{Na}$ passagem da "Teodiceia do trabalho" de Geórgicas I, 118-159, a introdução do trabalho e do sofrimento no mundo - e inclusive da agricultura - é apresentada como obra de Júpiter depois de destronar seu pai, o deus Saturno. Note-se também, com Monica Rachel Gale (2000, p. 61-62), que "o relato virgiliano da era pré-Júpiter faz lembrar da Idade Áurea de Hesíodo, mas o modo como o relato se introduz [...] corresponde ao começo da história prometeica. Isso é reforçado pela expressão abstrusum... ignem ('fogo oculto') [...], que faz lembrar do ocultamento do fogo pelo Zeus hesiódico" ("his account of the pre-Jovian age recalls Hesiod's Golden Age, but the way the account is introduced [...] corresponds to the beginning of the Prometheus story. This is reinforced by the phrase abstrusum ... ignem ('hidden fire') in 135, which recalls the hiding of fire by Hesiod's Zeus"). 
v. 180 - e, antes de mais nada, tantas pestes, conforme enunciadas a partir de v. 181 (rato, toupeiras, sapo, gorgulho e formiga).

Embora não divisemos acima, de fato, mais ampla e detida descrição das tarefas necessárias para fazer uma boa eira, ou mesmo do resultado assim obtido, com suas medidas e conformação visual, é inegável que a abordagem desse espaço, no trecho virgiliano em pauta, apresenta muitas correspondências com aquela conduzida tecnicamente, por exemplo, por Catão em De agri cultura (cap. XCI e CXXIX). A primeira dessas passagens catonianas, com efeito, já mencionava a necessidade de nivelar o solo da eira-coaequato et pauiculis uerberato, "nivela e bate com maças" - e avisava contra as ameaças representadas por formigas e ervas; ${ }^{5}$ na outra, de novo se trazia à tona a importância de nivelar o local - cylindro aut pauicula coaequato, "nivela com um cilindro ou um maça" - e ocorriam mais advertências sobre formigas neque formicae molestae erunt, "as formigas não causarão dano".

$\mathrm{Na}$ sequência do artigo, contudo, procuraremos apresentar evidências não de que as Geórgicas apenas "reflitam" a realidade dos campos itálicos nos tempos de Virgílio, mas sim de que construam um universo agrário sui generis. Semelhante forma de constituição de sentidos não deixa de passar, como se verá, pela própria distância estabelecida entre a figura do magister didático do poema e a vida rural, em sua dura concretude. Esse mesmo magister, vale ainda dizer, apresenta-se não só como autor de um poema - as próprias Geórgicas que se descortinam a nossos olhos -, mas também, nominalmente, sob o nome de Vergilius. ${ }^{6}$

${ }^{5}$ CATÃO, De agri cultura XCI: Si ita feceris, neque formicae nocebunt neque herbae nascentur. - "Se fizeres isso, as formigas não causarão danos e as ervas não brotarão". ${ }^{6}$ VIRGÍLIO, Geórgicas IV, 563-566: Illo Vergilium me tempore dulcis alebat Parthenope studiis florentem ignobilis oti,/ carmina qui lusi pastorum audaxque iunenta, / Tityre, te patulae cecini sub tegmine fagi. - "Naquele tempo, a doce Partênope nutria a mim,/ Virgílio, livre me dedicando a gostos de inglória calma,/ eu que fiz cantos de pastores e, por atrevimento juvenil,/ Títiro, celebrei-te sob o dossel da vasta faia". 


\title{
2 A caracterização do magister didático nas Geórgicas e seu distanciamento do âmbito rural do poema
}

O olhar para as características genéricas dos textos pertencentes à chamada "poesia didática" antiga revela-nos que as obras identificadas com essa categoria compositiva apresentam sem falta o traço chamado, por Katharina Volk (2002, p. 34), de "autoconsciência poética". Trata-se aqui de autores como Hesíodo (Os trabalhos e os dias), Tito Lucrécio Caro (De rerum natura), Ovídio (Ars amatoria) e Virgílio geórgico sempre se expressarem em suas respectivas obras apenas com a própria "voz" (ou a do magister didático) - sem, portanto, haver personagens que se representam diretamente ${ }^{7}$-, e de o fazerem, de modo explícito, como poetas:

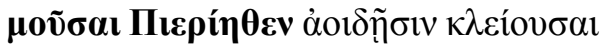

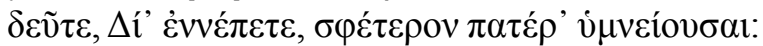

(HESÍODO, Os trabalhos e os dias 1-2. Grifos nossos) ${ }^{8}$

\author{
Auia Pieridum peragro loca nullius ante \\ trita solo. Iunat integros accedere fontis \\ atque haurire, iunatque nouos decerpere flores
}

\footnotetext{
${ }^{7}$ Nos diálogos agrários compostos por Marco Terêncio Varrão, em contrapartida, personagens variadas (Fundânio, Vácio, Mérula etc.) alternam-se a fim de explicar, com suas "próprias palavras" (em discurso direto), as muitas partes das técnicas agrícolas: Stolo cum aspexisset Scrofam, Tu, inquit, et aetate et honore et scientia quod praestas, dicere debes. Ille non grauatus, Primum, inquit, non modo est ars, sed etiam necessaria ac magna; eaque est scientia, quae sint in quoque agro serenda ac facienda, quo terra maximos perpetuo reddat fructus. - "Estolão, tendo olhado para Escrofa, disse: 'Tu, porque te avantajas pela idade, pela dignidade e pelo saber, deves falar'. Ele respondeu sem incomodar-se: 'Em primeiro lugar, não só é uma arte [a agricultura], mas ainda uma arte necessária e importante; e é a ciência do que se deve plantar e fazer em cada campo para que a terra produza os maiores rendimentos continuamente"' (VARRÃO, De re rustica I, III). A possibilidade de partição das "vozes" instrutivas, evidentemente, não é particularidade apenas do De re rustica varroniano, mas sim dos textos pertencentes ao gênero dialógico em geral.

8 “Musas Piérias que gloriais com vossos cantos,/ vinde! Dizei Zeus vosso pai hineando (tradução de M. C. N. Lafer. Grifos nossos).
} 
insignemque meo capiti petere inde coronam unde prius nulli uelarint tempora musae. (LUCRÉCIO, De rerum natura I, 926-930. Grifos nossos) ${ }^{9}$

Quid faciat laetas segetes, quo sidere terram uertere, Maecenas, ulmisque adiungere uitis conueniat, quae cura boum, qui cultus habendo sit pecori, apibus quanta experientia parcis, hinc canere incipiam. [...]

(VIRGíliO, Geórgicas I, 1-5. Grifos nossos) ${ }^{10}$

Os excertos dados nos mostram, em confirmação do dito acima, que seus autores indefectivelmente representam os magistri didáticos como poetas: em Hesíodo, a própria invocação às musas (Piérias), por se tratar de um elemento tradicional do início de textos poéticos desde Homero, opera para essa caracterização; em Lucrécio, que também menciona ao seu modo as mesmas Piérides, ocorre a construção de uma metáfora para apresentar o percurso de feitura do De rerum natura como "viagem" a uma zona desconhecida por outros; na propositio das Geórgicas, que mais nos interessa tendo em vista o presente contexto analítico, o prosseguimento da fala instrutiva do magister é designado pelo verbo canere ("cantar"), também encontrável em certo verso célebre da Eneida. ${ }^{11}$

Importante detalhe notado por Stephanie Nelson (1998, p. 93), no entanto, através do específico cotejo entre traços da obra hesiódica aludida e aqueles das Geórgicas, faz perceber fundamental ausência

\footnotetext{
9 "Percorro as lonjuras das Piérides, lugares nunca antes pisados/ pelos pés de alguém, agrada ir ter às fontes intocadas/ e beber, e agrada colher flores novas/ e dali buscar o notável coroamento de minha cabeça,/ donde, antes, as musas jamais cobriram as têmporas de alguém".

10 "O que torna as searas belas, sob qual astro a terra/ revirar, Mecenas, e unir as videiras aos olmos convém,/ qual o cuidado com os bois, que trato se dá ao termos/ rebanho, quanta experiência nas frugais abelhas, daqui começarei a cantar".

${ }^{11}$ VIRGÍLIO, Eneida I, 1-3: Arma uirumque cano Troiae qui primus ab oris/ Italiam, Fato profugus, Lauinique uenit/litora, [...] - "Canto as armas e o varão que primeiro, das praias de Troia,/ escape do destino, veio à Itália e às praias/ de Lavínio" (grifos nossos).
} 
na caracterização do professor que divisamos no último texto. Assim, observa a crítica, "Virgílio"12 nunca é retratado como fazendeiro ou algo próximo no poema didático em pauta, algo, de resto, em fragrante contraste com a caracterização de "Hesíodo" n'Os trabalhos e os dias. ${ }^{13}$ De fato, "Hesíodo" parece caracterizar-se ao modo simultâneo de um poeta e pastor em seu único poema didático, mas "Virgílio", em vez disso, identifica-se no máximo como um "poeta de agricultura" (NELSON, 1998, p. 93).

O efeito de distanciamento de "Virgílio" diante das realidades rústicas a que vai aludindo ao longo de seu magisterium, então, não se deve aos traços de um poeta ${ }^{14}$ associáveis a essa figura, mas antes ao

12 Para Nelson (1998, p. 93), "como Os trabalhos e os dias, as Geórgicas são um poema, não autobiografia" ("like the Works and Days, the Georgics is a poem, not an autobiography"). Isso sugere, acreditamos, que as figuras chamadas "Hesíodo" e "Virgílio" nessas obras não são meramente um espelhamento dos respectivos autores empíricos, mas sim construtos em alguma medida ficcionais, apesar da relativa sobreposição de seus contornos com os das personagens históricas que as compuseram. Notemos, então, que Virgílio, como autor empírico, realmente compôs as Bucólicas em sua juventude (veja-se acima nota 6). Ele também escreveu as Geórgicas, sob provável instigação de Mecenas (Geórgicas III, 40-41), e, depois dessa empreitada poética, de fato se dedicou a homenagear Otaviano Augusto elaborando um poema épico - não, exatamente, um "templo" (Geórgicas III, 16). Mas também não consta que tenha sido - à diferença do magister homônimo - efetivo professor de agricultura de alguém, sobretudo de Mecenas, o discipulus ("aluno") didático a que essa obra alude já em I, 2. Por esse motivo e visando a evitar confusões, tomamos sempre o cuidado de colocar entre aspas o nome da figura do magister em questão.

${ }^{13}$ NELSON, 1998, p. 93: "In the Works and Days Hesiod boasts about his poetic victory at Aulis. But we also hear about how Hesiod and his brother divided the farm, how their father came to have it, what kind of place it is". - "N'Os trabalhos e os dias, Hesíodo se orgulha de sua vitória poética em Áulis. Mas também ouvimos sobre como Hesíodo e seu irmão dividiram a fazenda, como seu pai veio a tê-la, que tipo de lugar ela é".

${ }^{14}$ Registre-se, de resto, que inclusive existe, nas literaturas clássicas, forte simbiose entre o ambiente campestre e certo tipo de poesia. Aqui nos referimos, na verdade, à poesia bucólica, na qual, tipicamente, pastores-poetas se dedicam à celebração do canto, da natureza e do amor enquanto inseridos em um universo, muitas vezes, tido como contraponto dos males urbanos (UREÑA PRIETO, 2001, p. 411-415). Veja-se também Virgílio, Bucólicas VIII, 68: Ducite ab urbe domum, mea carmina, ducite Daphnim. - "Trazei Dáfnis da cidade para casa, meus cantos, trazei Dáfnis". Nesse 
fato de que ele se mostra sob colorações, antes de tudo, urbanas. Certas palavras de Alexandre Dalzell (1996, p. 123) sobre as incongruências do magisterium agrícola das Geórgicas são bastante esclarecedoras quanto à face, na verdade, citadina de um professor que se coloca a preceituar a respeito da agricultura e da pecuária:

Addison tem uma ótima frase sobre o fato de Virgílio "lançar o esterco em roda com um ar gracioso". Lançar o esterco em roda não é, em absoluto, o que ele faz. Sua única menção ao assunto é caracterizada por certo pudor acanhado. "Não seja fastidioso", diz, "impregnar a terra com o rico estrume" (1.80). Fastio não é, pela minha experiência, um dos problemas do fazendeiro praticante. A atitude de Virgílio para com a fazenda é consistentemente urbana. (DALZELL, 1996, p. 123). ${ }^{15}$

A continuidade dos comentários de Dalzell (1996, p. 124) faz ainda ver como essa referência "acanhada" ao gesto, insistimos, essencial de adubar a terra com estrume não corresponde ao único ponto das Geórgicas que demonstra falta de adesão das palavras do magister ao universo rural focalizado, de um modo ou outro, no poema. Assim, antes de introduzir o tema da feitura da eira de debulha de cereais, de que já falamos, ele pede "licença" para não chocar as suscetibilidades do público avançando para assuntos de tamanha "trivialidade"; ${ }^{16}$ depois, no

poema, que tem como um de seus refrães o verso acima, o pastor Alfesibeu entretece uma espécie de ritual permeado por palavras propiciatórias, cujo objetivo era trazer de volta da cidade para o campo o puer amado, Dáfnis.

15 "Addison has a splendid phrase about Virgil 'tossing the dung about with an air of gracefulness', Tossing the dung about is not at all what Virgil does. His only reference to the subject is characterized by a kind of mealy-mouthed prissiness. 'Do not be too squeamish', he says, 'to soak the earth with rich dung' (1.80). Squeamishness is not, in my experience, one of the problems of the practicing farmer. Virgil's attitude to the farm is consistently urban".

${ }^{16}$ VIRGÍLIO, Geórgicas I, 176-177: Possum multa tibi ueterum praecepta referre,/ ni refugis tenuisque piget cognoscere curas. - "Posso contar-te muitos preceitos dos antigos,/ se não te esquivas nem te dá fastio conhecer cuidados pequenos". 
mesmo livro I (v. 228), ele continua a prever que se poderá vir a achar "desprezível" o tópico do cultivo da "lentilha pelusiana", ${ }^{17}$ como se, por um lado, seu público não fosse de fato constituído por camponeses e, por outro, tivesse pleno saber da existência de horizontes bem distintos daqueles meramente identificáveis com os limites da Itália rural.

Antes mesmo de adentrarmos o exame mais próximo de certos conteúdos técnicos das Geórgicas, pequenas brechas na compacidade puramente agrícola e didática do texto, como aquelas que acabamos de comentar no tocante a ser o professor/"Virgílio" não apenas imbuído de ares citadinos, mas no limite irônico quando se coloca tão "acima" de seus tópicos de ensino, já servem de entrada para modos de ler o poema afastados da ideia de algo linear e isento de planos significativos sobrepostos.

\section{Relativas inconsistências entre os elementos da vida rural nas Geórgicas e nos tempos do poeta}

Tendo compreendido, pelos dizeres prévios, que seria ingênuo ver no poema didático virgiliano, sem mais problematizações, simples e "comprometida" instrução a rudes praticantes de agricultura, ${ }^{18}$ deve-

${ }^{17}$ VIRGÍLIO, Geórgicas I, 227-230: Si uero uiciamque seres uilemque phaselum/ nec Pelusiacae curam aspernabere lentis, / haud obscura cadens mittet tibi signa Bootes; / incipe et ad medias sementem extende pruinas. - "Se, porém, plantares a ervilhaca e o vil feijão/ e não desprezares cuidar da lentilha pelusiana,/ Bootes, ao se pôr, há de dar-te não obscuros sinais;/ começa e prolonga a semeadura até o meio das geadas". ${ }^{18}$ Também contribui para o reforço desta ideia o fato de que, nas Geórgicas, o grau de elaboração do texto ultrapassa em muito o necessário pra que se produza a mínima comunicabilidade dos conteúdos técnicos. Seus livros parecem alternar-se, por exemplo, em uma sequência de tons "pessimistas" para os ímpares e "otimistas" para os pares (WILKINSON, 1997, p. 72); o poema conta, ainda, com intrincada malha intertextual, com a ocorrência de numerosas alusões a autores gregos e latinos dos tempos arcaicos até os escritos agrícolas de Marco Terêncio Varrão (VIRGIL, 1994, p. 10), contemporâneo do poeta; sua tessitura rítmica, sonora e imagética, por fim, alcança efeitos de grande beleza e funcionalidade significativa, sobretudo nas digressões, como a história de Orfeu que se narra em IV, 453-527 (OTIS, 1995, p. 200). O conjunto de tais dados parece claramente indicar que a composição do texto foi pensada para satisfazer às expectativas de um público, antes de mais nada, culto, citadino e habituado às sutilezas literárias e filosóficas de autores como Homero, Hesíodo, Arato de Solos, Lucrécio e outros. 
se agora passar, através do efetivo exame de alguns de seus conteúdos rústicos, à apresentação de dados para estabelecermos esse texto como, sobretudo, "fingimento" de uma situação de aula. Também vem a dar-se, conforme esperamos demonstrar, que várias imagens da ruralidade decorrentes das lições das Geórgicas escapem ao estritamente documental.

Alexander Dalzell (1996, p. 107), pronunciando-se a respeito dos modos de "Virgílio" conduzir seu curso de agropecuária na obra de nosso interesse, observou com acerto, em primeiro lugar, a relativa superficialidade no desenvolvimento de certos tópicos de instrução nas Geórgicas. Depois, que a seleção dos pontos a serem desenvolvidos no mesmo contexto de "ensino-aprendizado" não deixa de apresentar suas "estranhezas", como se, nesse último caso, fossem mesmo feitos deliberados recortes temáticos com vista a dotar a obra de contornos peculiares de significação.

No tocante à superficialidade, um exemplo possível, julgamos e, à sua maneira, trazido por Dalzell (1996, p. 107) corresponderia aos meros cinco versos nos quais as Geórgicas tematizam o tópico do cuidado com as oliveiras:

Contra non ulla est oleis cultura; neque illae

procuruam exspectant falcem rastrosque tenacis, cum semel haeserunt aruis aurasque tulerunt.

Ipsa satis tellus, cum dente recluditur unco, sufficit umorem, et grauidas, cum uomere, fruges.

(VIRGÍLIO, Geórgicas II, 420-424) ${ }^{19}$

Pelas palavras do crítico (Dalzell, 1996, p. 107), a passagem supracitada não faz jus à importância da cultura das oliveiras para a economia dos romanos. Ainda, como acrescenta, a abertura do mesmo

\footnotetext{
19 "Entretanto, nenhum cultivo requerem as oliveiras; nem elas/ esperam a foice curva e os ancinhos resistentes, / logo que se pegaram aos campos e aguentaram o vento./ A terra mesma bastante, quando é aberta com dente adunco,/ dá-lhes a umidade e, com a relha, pesadas colheitas".
} 
livro II das Geórgicas ${ }^{20}$ fazia crer que tal tipo de planta receberia, pela preceituação virgiliana, no mínimo tantos cuidados quantos aqueles concedidos às vinhas, ${ }^{21}$ essas de fato apresentadas com mais detalhamento ao longo da abordagem técnica dessa subdivisão do poema didático de Virgílio.

É possível endossar a primeira observação de Dalzell dizendo que, sem sombra de dúvida, a oleicultura ocupou papel notório no contexto econômico dos antigos fundi rustici romanos. Jean Andreau (2010, p. 90), assim, lembra-nos os muitos usos destinados ao azeite de oliveira no Mediterrâneo antigo, com empregos na alimentação, no cuidado dos corpos humanos e de animais (óleos de massagem e destinação medicinal etc.), nas lamparinas para iluminar edifícios, na lubrificação de couros... Isso, evidentemente, fazia desse item algo muito procurado pelos consumidores e, por conseguinte, objeto de preocupação produtiva, sobretudo, dos grandes proprietários de terras em Roma Antiga, dispostos a investir nelas com generosidade a fim de obter, como resultado, boas colheitas e lucros (ANDREAU, 2010, p. 88).

Desejamos também ressaltar que a oleicultura, do plantio das mudas de oliveira até o fabrico e venda do azeite, não correspondia a uma prática tão desprovida de cuidados quanto querem fazer crer tais palavras de "Virgílio". Desse modo, um tratado como o pequeno De agri cultura, de Catão Censor (séc. II a.C.), multiplica por toda sua extensão os capítulos dedicados a esclarecer o cultivo dessa planta ${ }^{22}$ e às etapas

${ }^{20}$ VIRGÍlLIO, Geórgicas II, 1-3: Hactenus aruorum cultus et sidera caeli:/ nunc te, Bacche, canam, nec non siluestria tecum/ uirgulta et prolem tarde crescentis oliuae. "Até aqui o cultivo dos campos e os astros do céu;/ agora a ti, Baco, cantarei, e contigo os brotos/ silvestres e a prole da oliveira que cresce tarde".

${ }^{21}$ DALZELL, 1996, p. 107: "The opening lines of Book 2, which list the principal subjects to be discussed, give the impression that the olive and the vine will be accorded equal treatment". - "Os versos iniciais do Livro 2, que listam os principais assuntos a serem discutidos, dão a impressão de que a oliveira e a videira receberão tratamento igual".

${ }^{22}$ CATÃO, De agri cultura VI: Ager oleto conserundo, qui in uentum fauonium spectabit et soli ostentus erit, alius bonus nullus erit. Qui ager frigidior et macrior erit, ibi oleam Licinianam seri oportet. - "O campo a ser cultivado como olival será voltado para o Favônio e exposto ao sol: nenhum outro será bom. Em campo mais frio e menos rico, é preciso que se plante a oliveira liciniana". 
de fabricação, ${ }^{23}$ armazenamento $^{24}$ e mesmo venda ${ }^{25}$ do(s) produto(s) correspondente(s).

Quando nos perguntamos pelos motivos dessa clara simplificação virgiliana na abordagem da oleicultura, que se contrapõe à complexidade e efetivo peso da mesma prática em De agri cultura, temos visto, podemos ir um pouco além da mera resposta de que apenas se trata de uma estratégia para não entediar o público original - urbano e letrado, bem o sabemos -, evitando a profunda focalização de tantos tópicos técnicos miúdos. Assim, de acordo com o mecanismo construtivo de

${ }^{23}$ CATÃO, De agri cultura LXIV: Olea ubi matura erit, quam primum cogi oportet, quam minimum in terra et in tabulato esse oportet. In terra et in tabulato putescit. Leguli uolunt uti olea caduca quam plurima sit, quo plus legatur; factores, ut in tabulato diu sit, ut fracida sit, quo facilius efficiant. Nolito credere oleum in tabulato posse crescere. - "Quando a azeitona estiver madura, é preciso que seja colhida o quanto antes e fique o menos possível na terra e no tabulado. Na terra e no tabulado, apodrecerá. Os catadores desejam que sejam muitas as azeitonas caídas, para que se colham em menor número; os azeiteiros, que permaneçam no tabulado por longo tempo e amoleçam, para trabalharem mais facilmente. Não julgues que o azeite possa aumentar de quantidade no tabulado".

${ }^{24}$ CATÃO, De agri cultura XIII: In cellam oleariam haec opus sunt. Dolia olearia, opercula, labra olearia XIIII, concas maioris II et minoris II, trullas aheneas tris, amphoras olearias II, urceum aquarium I, urnam quinquagenariam I, sextarium olearium I, [...]. - "Para o depósito de azeite, isto é preciso: dolia para azeite com tampas, quatorze cubas para azeite, dois recipientes grandes, dois pequenos, três escumadeiras de bronze, duas ânforas para azeite, um pote para água, um vaso grande que comporte cinquenta heminas, um medidor para azeite com capacidade para um sextário, [...]". ${ }^{25}$ CATÃO, De agri cultura CXLVI: Oleam pendentem hac lege uenire oportet. Olea pendens in fundo Venafro uenibit. Qui oleam emerit, amplius quam quanti emerit omnis pecuniae centesima accedet, praeconium praesens SS.L, et oleum: Romanici P. $x x D$, uiridis $P$. CC, oleae caducae M. L, strictiuae M. X modio oleario mensum dato, unguinis P. X; ponderibus modiisque domini dato frugis primae cotulas duas. - "É preciso vender as azeitonas no pé sob estas condições: para as azeitonas no pé a serem vendidas em uma propriedade em Venafro, seu comprador juntará um por cento do total além da quantia de compra; cinquenta sestércios pelo trabalho do pregoeiro; que se paguem mil e quinhentas libras de azeite romano, duzentas libras de azeite verde, cinquenta módios de azeitonas caídas, dez módios de azeitonas apanhadas (que sejam medidas com um módio para azeitonas) e dez libras de azeite lubrificante; que dê duas cótilas da primeira prensagem para usar os pesos e medidas do senhor". 
alternância em chiaroscuro ${ }^{26}$ encontrável ao longo dos quatro livros das Geórgicas (o qual não deve, porém, ser levado às raias do absoluto), ${ }^{27}$ tem-se que uma seção como o livro II, na verdade, manifeste certo tom de alegria e leveza.

Contribui para isso a predominância dos assuntos em nexo com a viticultura nos versos dessa parte da obra, de tal modo que, embora trabalhoso em suas muitas etapas, ${ }^{28}$ o plantio das parreiras não deixa de trazer saborosos frutos: aqui nos referimos às uvas, mas, sobretudo, ao vinho, atributo em forte associação com os dons báquicos no poema. ${ }^{29}$ Ainda, logo ao início de Geórgicas II encontramos dizeres que vêm, justamente, ressaltar a espontânea produtividade das árvores de certas espécies:

\footnotetext{
${ }^{26}$ Veja-se nota 18.

${ }^{27}$ Um pormenor de Geórgicas II foi evocado por Monica Rachel Gale (2000, p. 36) a fim de demonstrar que o "tom confiante e descomplicado" que se encontra em inícios desse livro - e prevalece em várias de suas partes - é problematizado em v. 455-457. Esses três versos, com efeito, abordam a lenda dos sangrentos combates entre seres humanos e centauros (embriagados de vinho) durante as bodas de Pirítoo, o amigo de Teseu, e Hipodâmia, como se, observa a crítica, neles se introduzissem sombras evocativas do fato de que os deuses e suas "dádivas" - como Vênus e o amor no De rerum natura lucreciano - ora favorecem, ora destroem os mortais.

${ }^{28}$ VIRGÍLIO. Geórgicas II, 397402: Est etiam ille labor curandis uitibus alter, cui numquam exhausti satis est: namque omne quotannis/ terque quaterque solum scindendum glaebaque uersis/ aeternum frangenda bidentibus, omne leuandum/ fronde nemus. Redit agricolis labor actus in orbem/ atque in se sua per uestigia uoluitur annus. - "Há ainda aquele outro trabalho do cuidado das vinhas,/ o qual nunca está suficientemente terminado: com efeito, a cada ano/ todo o solo três e quatro vezes deve ser fendido e os torrões quebrados sem cessar/ virandose as enxadas, todo o bosque/ deve ser aliviado das folhas. O trabalho feito volta em círculo para os agricultores,/ gira o ano sobre si por suas próprias pegadas".

${ }^{29}$ A menção ao deus ocorre já no proêmio deste livro, quando o poeta o invoca com palavras festivas que incluem o "campo florescente e carregado pelo outono cheio de pâmpanos" - pampineo grauidus autumno/ floret ager, v. 5-6 -, a "vindima a espumar em cubas cheias" - spumat plenis uindemia labris, v. 6-e as "pernas tingidas em mosto novo" - musto/ tinge nouo... crura, v. 7-8. Sua presença, ainda, multiplica-se ao longo do livro II porque Virgílio, várias vezes, prefere empregar metonimicamente o nome do deus a dizer, por exemplo, uinea ("vinha").
} 
Principio arboribus uaria est natura creandis. Namque aliae nullis hominum cogentibus ipsae sponte sua ueniunt camposque et flumina late curua tenent, ut molle siler lentaeque genistae, populus et glauca canentia fronde salicta.

(VIRGÍLIO, Geórgicas II, 9-13. Grifos nossos) ${ }^{30}$

Então se constrói, nessa subdivisão do poema, tanto pela facilitação dos preceitos vinculados à cultura da oliveira, quanto pela ideia de uma natureza menos avara, em que encontramos até certas "dádivas" divinas, uma imagem da vida no campo em relativo contraste com a dureza do cultivo dos cereais, ${ }^{31}$ como se mostrava no livro I. Nisso, é forçoso repisar, ocorre deliberado esforço para a moldagem da obra segundo princípios compositivos que acabam por organizála poeticamente, mais do que com efetivos intentos de informar e "documentar" sobre a lida rural antiga.

De novo recorrendo aos instrumentos analíticos levantados por Dalzell (1996, p. 107), além da superficialidade na abordagem de muitos assuntos rústicos que adentram as Geórgicas, também o critério da "seletividade" contribui para dotar esse poema de contornos bastante peculiares, do ponto de vista do magisterium que veicula. Tudo se dá, nesse sentido, como se o autor tivesse optado, no contraste inclusive com outras

30 "Primeiro, é variável a natureza de propagar as árvores./ Com efeito algumas, sem coação humana alguma, por si/ vêm espontaneamente e, com vastidão, a campos e rios/ sinuosos dominam, como o delicado vime e as flexíveis giestas,/ o choupo e os salgueiros branquejantes na verde folhagem".

${ }^{31}$ TREVIZAM, 2014, p. 190-191: "O livro I das Geórgicas virgilianas descortina ao leitor o espetáculo da luta humana pela sobrevivência diária, fruto do trabalho de nossas mãos, segundo descrito pelo poeta: é essa a parcela da obra em que se concentram preceitos didáticos em nexo com o plantio dos campos cerealistas, donde nos vem o pão, símbolo por excelência da vida material civilizada. Nesse contexto, como muitas e, por vezes, penosas são descritas as várias operações de cultivo necessárias, a exemplo da primeira arada do solo (v. 43-46), da escolha das sementes (v. 197-200), da feitura de uma eira para debulha das espigas (v. 176-186) e da adubação (v. 80)". 
obras de teor agrário compostas na Antiguidade, ${ }^{32}$ sobretudo por incorporar a esse texto tópicos temáticos propiciadores de efeitos poéticos rendosos, no tocante a seu potencial para repercutir vasta gama significativa.

Importantes exemplos dados pelo crítico anglófono dizem respeito, dessa maneira, a que o livro III das Geórgicas conceda grande relevo à criação de equinos, enquanto o livro IV se concentra, sob o aspecto didático, em preceituar somente sobre a apicultura. Quanto ao primeiro desses pontos, deve-se de início observar com o estudioso ${ }^{33}$ que de fato havia outros animais um tanto mais presentes na rotina dos trabalhos agrícolas, tal como praticados na Itália de Virgílio, que os cavalos.

Para efeitos de transporte ligeiro de cargas, assim, bem como na tração de certas máquinas rústicas, sobretudo as mós (ROBERT, 1985, p. 269), os burros eram bestas de uso valiosíssimo na lida agrária romana. ${ }^{34}$

${ }^{32}$ No supracitado De re rustica, Varrão desenvolveu, em seu segundo diálogo, vários assuntos em relação com a pecuária. Os tipos de animais que recebem tratamento técnico, ou comentários, o longo dessa parte de sua obra agrícola, portanto, são os ovinos, os caprinos, os suínos, os bovinos, os asininos, os equinos, os "mulos" (híbridos de égua e burro) e os cães. No terceiro diálogo de De re rustica, por sua vez, surgem muitos tópicos atinentes ao que se conhecia como uillatica pastio no mundo antigo: tratava-se de criações de pequenos animais (aves, peixes, abelhas, caracóis, arganazes etc.) nas imediações da sede das propriedades rurais romanas, as chamadas uillae rusticae. Evidentemente, o que justifica a ampla partição dos assuntos sobre criação animal nesse último diálogo varroniano é o fato de que ali divisamos, embora de forma sintética, verdadeiro esforço do autor por compilar saberes de utilidade para efetivos proprietários de terras. Diga-se, ademais, que várias dessas criações resultavam em produtos bastante valorizados financeiramente na hora da venda (ANDREAU, 2010, p. 95), assim se entendendo que os grandes donos de terras romanos, que constituíram o público original do De re rustica, podem ter tido, na verdade, grande interesse por informar-se sobre como conduzir com apuro as operações destinadas a obtê-los.

${ }^{33}$ DALZELL, 1996, p. 107: "The horse was not an important animal on the Italian farm; yet it is given epic treatment, while the useful mule and donkey are passed over". - "O cavalo não era um animal importante na fazenda itálica; entretanto, recebe tratamento épico, enquanto os úteis asno e burro são omitidos".

${ }^{34}$ VIRGÍLIO, Geórgicas I, 273-275: Saepe oleo tardi costas agitator aselli/ uilibus aut onerat pomis, lapidemque reuertens/ incusum aut atrae massam picis urbe reportat. - "Com frequência, o condutor onera com azeite ou com frutos comuns/ o costado do burrinho lento, e, tornando da cidade,/ traz a mó picotada ou a massa do negro piche". 
Também não nos podemos esquecer de que o animal símbolo da vida camponesa foi, na Grécia e em Roma Antiga, o boi, por sua evidente utilidade no transporte de cargas de maior monta - as quais podia arrastar sobre carros -, e, é evidente, por sua parceria com o agricultor na estafante tarefa de arar o solo. Tamanha importância concedida aos bovinos, que se desdobrou até para aspectos legais, ${ }^{35}$ tornaria, de fato, imperdoável que não se focalizasse alguma preceituação do livro III das Geórgicas, mesmo que de modo simplificado, sobre tal espécie. Isso, na verdade, ocorre entre v. 51-59; v. 138-178 etc.

Mas animais de caráter marcadamente humilde, como os burros e suínos, não recebem cobertura alguma ao longo dos versos de Geórgicas III, devendo-se a propósito lembrar que, depois de concentrar-se na abordagem técnica dos cavalos e bois na parte inicial desse livro, Virgílio

${ }^{35}$ MORGAN, 1999, p. 109: "We find numerous references in ancient texts to a preeminence among domestic animals attributed to the ox which is such as to accord oxen a status almost equivalent to human. According to Varro (Rust. 2.5.3; cf. Columella 6 praef. 7), killing an ox had in the past been a capital offence. The ox was the socius hominum in rustico opere, 'the partner of mankind in agricultural work', and as such equivalent to, and as inviolable as, a human fellow-worker. Similarly, Pliny the Elder cites a case where a man who killed an ox, his socium... laboris agrique culturae, "partner in work and agriculture', had been punished just as if he had killed his farm-labourer (HN 8.180; cf. Val. Max. 8.1 damnat). Ovid also has Pythagoras make much of this close relationship between man and ox (Met. 15.120-42). Aelian makes the point explicit, stating that in Athens it was not permitted to sacrifice a plough-ox, 'because it also was a farmer and partner in human labours' (VH 5.14; cf. NA 2.57)". - "Encontramos numerosas referências, nos textos antigos, à proeminência, entre os animais domésticos, atribuída ao boi, a qual chega ao ponto de destinar-lhes um status quase equivalente ao humano. De acordo com Varrão (Rust. 2.5.3; cf. Columella 6 praef. 7), matar um boi fora no passado um crime capital. $\mathrm{O}$ boi era o socius hominum in rustico opere, 'parceiro da humanidade no trabalho camponês', e, como tal, equivalente e tão inviolável quanto um companheiro de trabalho humano. Similarmente, Plínio, o Velho, cita um caso em que um homem que matou um boi, seu socium... laboris agrique culturae, 'companheiro... de labuta e na agricultura', fora punido exatamente como se tivesse matado seu auxiliar rústico ( $H N$ 8.180; cf. Val. Max. 8.1 damnat). Ovídio também mostra Pitágoras dando muita atenção a tal relacionamento próximo entre homem e boi (Met. 15.120-42). Eliano explicita a questão, declarando que, em Atenas, não era permitido sacrificar um boi de arado 'porque também era um fazendeiro e parceiro na labuta humana' (VH 5.14; cf. NA 2.57)”. 
inseriu nele um "segundo proêmio" (v. 286-294) e passou a oferecer explicações atinentes a animais de menor porte (ovinos e caprinos, apenas).$^{36}$ Não obstante, sabemos que a criação de porcos teve ampla difusão na economia rural dos antigos, pois, como relata Jean-Noël Robert (1985, p. 275), essa espécie foi das mais apreciadas pela culinária romana, conhecendo-se inúmeras preparações alimentícias - das mais populares às mais refinadas - a terem sua carne como base. Além disso, a relativa facilidade de alimentá-los - trata-se de animais que comem quase tudo - acabou por difundir sua criação por, praticamente, a Itália inteira (ROBERT, 1985, p. 275), em que pesem os pejos de quaisquer poetas de incluí-los com outras espécies em suas obras, por razões vinculadas à "banalidade".

Tornando, contudo, a uma das estrelas da exposição zoológica em Geórgicas III, os equinos, pode-se dizer que a própria ambientação épica de partes desse livro favorece a incorporação de um tipo animal tão nobre a seus versos. Os leitores do poema, dessa forma, lembramse de que, entre v. 13 e v. 39, encontra-se a célebre metáfora da futura edificação de um "templo de mármore" - templum de marmore ponam, v. 13 - às margens do rio Míncio, situado na Mântua natal de Virgílio. Ora, segundo certa convenção de representar a feitura de um poema como edificação de uma obra arquitetônica, a qual parece remontar pelo menos a Píndaro, ${ }^{37}$ tem-se tradicionalmente entendido que se faça

${ }^{36}$ Tais animais, igualmente humildes, encontravam-se, porém, bem assimilados pela cultura literária antiga, a qual, desde Teócrito de Siracusa - autor dos Idílios no séc. III a.C. - , celebrara entre outros assuntos a rotina do trato de rebanhos por rudes pastores (UREÑA PRIETO, 2001, p. 412).

${ }^{37}$ WILKINSON, 1997, p. 168: "The symbolism of the temple and its adornment that follows is remarkable: it was not common in Antiquity to visualize poetry in terms of architecture and sculpture. But it was quite common in Pindar: 'Raising upon golden pillars the fair-walled porch of our chamber, we shall construct, as it were, a splendid hall, and to begin our work we must set up a front that will shine afar'. 'There has been built in Apollo's valley for the prosperous Emmenidae and for Xenocrates a Pythian victor's treasure-house of song... And the front shall proclaim in pure brightness... a famous victory won with the chariot in the vale of Crisa". - "O simbolismo do templo e de sua ornamentação, que se segue, é notável: não foi comum, na Antiguidade, visualizar a poesia em termos de arquitetura e de escultura. Mas foi muito comum 
referência, no trecho, à posterior escrita da Eneida, um poema de todo épico e belicoso, pelo mesmo poeta.

Concretamente, na passagem sob exame, destacam-se do ponto de vista da epicização desse poema didático o posicionamento mesmo de Otaviano - Caesar, v. 16 - no centro do "templo"/futuro poema de Virgílio, algo que não deixa de prefigurar o papel de destaque da casa imperial reinante, sobretudo, ao "meio" - canto VI - da Eneida; ${ }^{38}$ a imagem triunfal que se associa a "Virgílio" depois de ter, "com sucesso" uictor, v. 17 -, trazido as musas da Aônia para Mântua; ${ }^{39}$ a representação da "batalha contra os gangáridas"/hindus - Gangaridum... arma, v. 27 - na porta entalhada do mesmo "templo", a que se juntam menções a lutas contra os egípcios, Partos e outros povos.

Diga-se, ainda, que a representação em si da figura do cavalo assume, em Geórgicas III, tons que podemos caracterizar como épicos:
Continuo pecoris generosi pullus in aruis
altius ingreditur et mollia crura reponit.
Primus et ire uiam et fluuios temptare minantis
audet et ignoto sese committere ponti

em Píndaro: 'Erigindo sobre pilares de ouro o alpendre com belas paredes de nosso aposento, construiremos, por assim dizer, um esplêndido salão; e, para começar nossa obra, devemos levantar uma fachada que resplandecerá de longe'. 'Edificou-se no vale de Apolo, para os prósperos Emênidas e para Xenócrates, um tesouro musical do pítico vencedor... E sua fachada anunciará, em puro brilho... uma vitória famosa, obtida pela carruagem no vale de Crisa"'.

${ }^{38}$ VASCONCELLOS, 2014, p. 59-60: "Segue-se [no canto VI da Eneida] a revista dos futuros heróis romanos: as almas que neles se encarnarão um dia como que desfilam diante de Anquises, que lhes tece o louvor. Mas o episódio termina com uma nota sombria, quando Anquises faz o elogio fúnebre do jovem Marcelo, sobrinho de Augusto e esperança de sua sucessão, que morrera jovem".

${ }^{39}$ VIRGÍLIO, Geórgicas III, 17-18: Illi uictor ego et Tyrio conspectus in ostro/ centum quadriiugos agitabo ad flumina currus. - "Para ele eu, vencedor e visivel em ostro de Tiro,/ tocarei cem quadrigas junto do rio" (grifos nossos). Veja-se também Bornecque e Mornet (2002, p. 113) a respeito do aparato presente no triunfo: "O triunfador, num carro dourado, em forma de torre, atrelado a quatro cavalos brancos; sentado numa cadeira curul, trajando uma túnica bordada e uma toga de púrpura bordada a ouro, levava à mão um cetro de marfim e à cabeça uma coroa de louro" (grifos nossos). 
nec uanos horret strepitus. Illi ardua ceruix argutumque caput, breuis aluus obesaque terga, luxuriatque toris animosum pectus. Honesti spadices glaucique; color deterrimus albis et giluo. Tum, si qua sonum procul arma dedere, stare loco nescit, micat auribus et tremit artus collectumque fremens uoluit sub naribus ignem. Densa iuba et dextro iactata recumbit in armo; at duplex agitur per lumbos spina, cauatque tellurem et solido grauiter sonat ungula cornu.

(VIRGÍLIO, Geórgicas III, 75-88) ${ }^{40}$

$\mathrm{Na}$ verdade, traços como a coragem do animal descrito nesses versos - v. 77-79 -, sua ambientação em um entorno que não deixa de incluir o "ressoar das armas" - v. 83 - e o "revolver, sob as narinas, do fogo recolhido" - v. 85 -, ${ }^{41}$ parecem furtá-lo ao âmbito estrito da vida rural para inseri-lo em um plano evocativo de algo mais sublime. Além da atribuição de destaque aos equinos pelo viés belicoso, também sua associação a várias lendas da mitologia contribui para revesti-los, no poema, de uma aura imaginativa afastada da banalidade: em Geórgicas III, 89-94, mencionam-se um cavalo mítico chamado Cílaro, as parelhas de Marte e a junta de Aquiles, sem esquecimento da lenda a envolver uma metamorfose do deus Saturno em equino para escapar-se de ser

40 "Logo o potro de boa raça marcha mais altivo/ nos campos e avança as pernas flexíveis. Primeiro/ ousa pôr-se a caminho, experimentar rios ameaçadores/ e entregar-se a uma ponte desconhecida, nem se apavora/ com ruídos sem importância. Tem a nuca alta/ e a cabeça afilada, o ventre pequeno, o dorso gordo,/ o peito intrépido abunda em músculos. Bons os baios/ e de olhos verdes, a pior cor têm os brancos e o cinza-escuro./ Então, se em algum ponto ao longe as armas ressoaram,/ não sabe parar no lugar, remexe as orelhas, faz tremer/ os membros e, fremente, revolve sob as narinas fogo recolhido./ A crina é densa e pende lançada na espádua direita;/ mas a espinha se estende dos dois lados pelos lombos/ e a pata escava a terra e ressoa forte com o casco duro".

${ }^{41} \mathrm{Na}$ verdade, essa imagem provavelmente fora tomada, por Virgílio, de Lucrécio (De rerum natura V, 30: et Diomedis equi spirantes naribus ignem - "e os cavalos de Diomedes que respiram fogo pelas narinas"), evidenciando-se assim toda uma cadeia intertextual interna à poesia didática latina. 
flagrado em adultério com a ninfa Fílira; ${ }^{42} \mathrm{em}$ III, 113-117, certas relações de Erictônio e dos lápitas - míticos inimigos dos centauros - com a domesticação de cavalos; ${ }^{43}$ em III, 266-268, o poeta traz à tona uma sombria lenda, segundo a qual Glauco, filho de Sísifo, teria sido atacado a dentadas e morto por suas próprias éguas inflamadas de desejo, às quais negara o coito pretendido com os machos. ${ }^{44}$

No tocante à seleção não dos cavalos, mas sim das abelhas, para constituírem um polo de atenção privilegiado (na verdade, o único, em termos das espécies animais associáveis à uillatica pastio e abordadas no livro em pauta) em Geórgicas IV, devemos notar que, dentre todos os tipos zoológicos focalizados por Marco Terêncio Varrão no terceiro diálogo de De re rustica, ${ }^{45}$ apenas esses artrópodes conseguem assumir contornos tão sugestivos. Com isso nos reportamos a que pontos afins não só ao caráter gregário das abelhas, mas ainda a seu forte empenho nos trabalhos da colmeia, à regrada divisão de tarefas no interior desse espaço e mesmo a aspectos de "veneração" encontráveis em sua imagem,

${ }^{42}$ VIRGÍLIO, Geórgicas III, 89-94: Talis Amyclaei domitus Pollucis habenis/ Cyllarus et, quorum Grai meminere poetae,/ Martis equi biiuges et magni currus Achillei;/ talis et ipse iubam ceruice effundit equina/ coniugis aduentu pernix Saturnus et altum/Pelion hinnitu fugiens impleuit acuto. - "Assim Cílaro domado pelas rédeas de Pólux/ amicleu e, de que os poetas gregos se lembram,/ os cavalos emparelhados de Marte e a junta do grande Aquiles./ Assim também o próprio Saturno espalha a crina na nuca equina,/ ligeiro à chegada da esposa, e, fugindo,/ encheu o alto Pélion com um relincho agudo". ${ }^{43}$ VIRGÍLIO, Geórgicas III, 113-117: Primus Ericthonius currus et quattuor ausus/ iungere equos rapidusque rotis insistere uictor./ Frena Pelethronii Lapithae gyrosque dederel impositi dorso atque equitem docuere sub armis/ insultare solo et gressus glomerare superbos. - "Erictônio ousou, sendo pioneiro, unir os carros/ e quatro cavalos e, vencedor impetuoso, firmar-se sobre rodas./ Os lápitas de Peletrônio, postos sobre o dorso, criaram os freios/ e as voltas e ensinaram o cavaleiro armado/ a saltar sobre o solo, a seguir em galope pomposo".

${ }^{44}$ VIRGÍLIO, Geórgicas III, 266-268: Scilicet ante omnis furor est insignis equarum/ et mentem Venus ipsa dedit, quo tempore Glauci/ Potniades malis membra absumpsere quadrigae. - "Naturalmente, antes de tudo é admirável o furor das éguas,/ e a própria Vênus inspirou o sentimento, quando éguas/ potníades, atreladas em quatro, devoraram os membros de Glauco com suas mandíbulas".

${ }^{45}$ Veja-se nota 32. 
tal como delineada na obra virgiliana ${ }^{46}$ acabam por dotar a espécie citada de ressonâncias, de algum modo, "humanas".

Apesar de algumas reservas que fazemos quanto à plena identificação entre as abelhas e o Estado romano, como se se tratasse a figuração da colmeia de uma alegoria ligada ponto a ponto com essa sociedade ${ }^{47}$ não deixa de ser possível ver em elementos de Geórgicas IV alguma semelhança, inclusive, com a situação política de Roma nos tempos da escrita do poema:

O mito de Aristeu não é só o final para um grande poema didático, mas ainda uma alegoria para Otaviano e Antônio, cuja luta pelo poder alcançou seu ápice em setembro de 31 a.C.; Virgílio acabou as Geórgicas dois anos depois. A narrativa é uma referência funcional a Otaviano (o apicultor) e a seus adversários Antônio e Cleópatra, talvez também a Sexto Pompeu. A história oscila, por assim dizer, entre Aristeu que nos lembra de Otaviano e o mesmo Aristeu que é Antônio. No fim da história, OtavianoAristeu é o vencedor da luta pelo poder quando assume controle sobre as abelhas, ou seja, o Estado romano. [...] A história oscila entre, de um lado, o senso de dever de Otaviano para restaurar a ordem e trazer a paz e, de outro, a aliança destrutiva entre Antônio e Cleópatra. (WEEDA, 2015, p. 98). ${ }^{48}$

${ }^{46}$ VIRGÍLIO, Geórgicas IV, 210-214: Praeterea regem non sic Aegyptus et ingens/ Lydia nec populi Parthorum aut Medus Hydaspes/ obseruant. Rege incolumi mens omnibus una est;/ amisso rupere fidem constructaque mella/ diripuere ipsae et crates soluere fauorum. - "Ademais, não assim ao rei o Egito e a Lídia ingente,/ nem os povos da Pártia ou o Medo do Hidaspes/ veneram. Salvo o rei, todas têm um só sentir;/ se falta, a fé violaram, os méis reservados/ elas mesmas saquearam e soltaram as redes dos favos". ${ }^{47}$ DALZELL, 1996, p. 123: "The bees of the Georgics have some very un-Roman characteristics: they are sexless, for example, and they prostrate themselves before their kings like oriental courtiers". - "As abelhas das Geórgicas possuem certas características um tanto antirromanas: elas são, por exemplo, assexuadas, e prostram-se diante de seus reis como cortesãos orientais".

48 "The myth of Aristaeus is not just the end to a great didactic poem, but also an allegory for Octavian and Antony, whose struggle for power had reached its height in 
A história mítica a que o trecho transcrito alude refere-se à perda de suas abelhas por Aristeu, herói-civilizador ${ }^{49}$ inserido no epýllion do livro IV das Geórgicas (v. 315-558). Na verdade, depois de perseguir Eurídice, esposa de Orfeu, pelas margens de um rio, a moça em fuga pisou por acidente sobre uma serpente venenosa e morreu. Disso resultou o desespero de Orfeu e sua descida com vida aos Infernos, a fim de resgatála; depois do insucesso da tentativa, esse cantor mítico partiu desvairado para a Trácia, onde as Bacantes o desmembraram vivo.

Uma espécie de vingança dos Manes - "almas divinizadas" ofendidos de Orfeu e Eurídice, desse modo, correspondeu às causas da mortandade das abelhas de Aristeu, tendo sido necessário que ele as recuperasse através do rito da bugonia, cuidadosamente descrito em Geórgicas IV, 281-314 e implicando no sacrifício de reses. As análises de Weeda (2015), como vimos, retomam esses elementos da narrativa para vinculá-los ao aspecto histórico das Guerras Civis romanas, cujos principais oponentes, em sua fase decisiva, foram Marco Antônio, aliado à rainha Cleópatra do Egito, e Otaviano, o futuro imperador Augusto. Devemos esclarecer que um fator a contribuir para o embasamento dessa leitura é que, entre v. 67-76, de fato se descreve uma batalha entre abelhas; ${ }^{50}$ além disso, a passagem identificada com v. 86-94 contrapõe

September 31 B.C.; Vergil finished the Georgics two years later. The narrative is a functional reference to Octavian (the beekeeper), and to his adversaries Antony and Cleopatra, and perhaps also to Sextus Pompeius. The story oscillates, as it were, between Aristaeus who reminds us of Octavian and the same Aristaeus who is Antony. At the end of the story 'Octavian-Aristaeus' is the winner of the struggle for power when he assumes control over the bees, that is, the Roman state. [...] The story oscillates between, on the one hand, the sense of duty of Octavian to restore order and bring peace and, on the other hand, the destructive alliance of Antony and Cleopatra".

${ }^{49}$ GRIMAL, 1963, p. 51: "Les nymphes lui enseignèrent aussi l'art de la laiterie et l'élévage des abeilles, ainsi que la culture de la vigne. À son tour, il apprit aux hommes ce que les déesses lui avaient enseigné". - "As ninfas também lhe ensinaram a arte dos laticínios e a criação de abelhas, assim como o cultivo da videira. Por sua vez, ele ensinou aos homens o que as deusas the haviam ensinado".

${ }^{50}$ VIRGÍLIO, Geórgicas IV, 67-76: Sin autem ad pugnam exierint-nam saepe duobus/ regibus incessit magno discordia motu;/ continuoque animos uolgi et trepidantia bello/ corda licet longe praesciscere; namque morantis/Martius ille aeris rauci canor 
dois chefes de colmeias em conflito, um dado como "inferior" - e merecedor da morte -, outro, como "melhor". ${ }^{51}$

O último dado que desejamos apontar, em relação com os desvios da vida e das práticas rurais, tal como mostradas nas Geórgicas, diante de um quadro mais "real", historicamente, do que foi essa mesma ruralidade na Itália antiga diz respeito a uma importante questão trazida à tona pelas análises de Philip Thibodeau (2011, p. 41 et seq.). Com efeito, o estudioso de língua inglesa aponta, em capítulo de uma obra crítica inteira dedicada às Geórgicas, que, sem haver necessariamente o pleno apagamento de quaisquer menções ao trabalho escravo nos versos do poema, ${ }^{52}$ ao menos a um tipo peculiar de cativo especializado - o uilicus - coube a exclusão, no contexto em jogo.

increpat, et uox/ auditur fractos sonitus imitata tubarum;/ tum trepidae inter se coeunt, pennisque coruscant/ spiculaque exacuunt rostris aptantque lacertos/ et circa regem atque ipsa ad praetoria densael miscentur magnisque uocant clamoribus hostem. "Mas se saírem ao combate, pois amiúde a discórdia/ entre dois reis sobreveio com grande tumulto,/ logo os ânimos da plebe e os peitos na guerra/ palpitantes é possível muito antes pressentir; na verdade, aquele canto/ marcial do bronze rouco aguilhoa as que hesitam e ouve-se/ uma voz imitativa dos ruidosos sons das tubas;/ então, juntamse entre si a tremer, agitam suas asas,/ afiam os ferrões com as trombas, preparam os músculos/ e, em torno do rei, bem como junto à tenda mesma do líder, emaranham-se/ em massa e provocam os inimigos com grande clamor".

${ }^{51}$ VIRGÍLIO, Geórgicas IV, 88-94: Verum, ubi ductores acie reuocaueris ambo,/ deterior qui uisus, eum, ne prodigus obsit,/ dede neci; melior uacua sine regnet in aula./ Alter erit maculis auro squalentibus ardens/ (nam duo sunt genera): hic melior insignis et ore/ et rutilis clarus squamis; ille horridus alter/ desidia latamque trahens inglorius aluom. - "Mas, quando tirares os dois chefes da frente de batalha,/ o que parecer pior, para não prejudicar consumindo,/ entrega à morte; deixa que o melhor reine em um palácio desimpedido./ Um será brilhante com manchas incrustadas de ouro;/ pois há dois tipos: este é o melhor, notável pelo aspecto/ e reluzindo com suas escamas ardentes, aquele outro é asqueroso/ e arrasta inglório na indolência um ventre volumoso".

${ }^{52}$ THIBODEAU, 2011, p. 45: "The claim is commonly made that Vergil omits slavery from the poem. This is not entirely accurate: he refers obliquely to runaway slaves (fugae, 1.286), and gives instructions for 'enslaving' a young steer (seruitio adsuerint, 3.168)". - "É comumente feita a alegação de que Virgílio omite a escravidão do poema. Isto não é de todo exato: ele se refere obliquamente a escravos fugitivos (fugae, 1.286), e dá instruções para 'escravizar' um boi jovem (seruitio adsuerint, 3.168)". 
Primeiro devemos dizer que essa última personagem, bastante bem documentada na literatura agrária romana desde o De agri cultura de Catão Censor, foi uma espécie de administrador dos grandes fundi rustici antigos, responsável por sua condução prática inclusive durante as usuais ausências do dono das terras. Tratava-se, dessa forma, de uma peça fundamental no maquinário produtivo organizado e, em grande escala, escravista em que se tornaram as terras dos "notáveis" latinos, como os membros das ordens senatorial e equestre dedicados a essa maneira de ganho, sobretudo a partir das mudanças socioeconômicas advindas com a expansão romana no Mediterrâneo Ocidental. ${ }^{53}$

O motivo aventado por Thibodeau $(2011$, p. 45) para a retirada do uilicus dos horizontes funcionais da "fazenda" nas Geórgicas tem relações, como acredita, com evitar-se a concorrência entre tal figura e a do agricola ${ }^{54}$ - "agricultor", por isso se entendendo sobretudo o pater

\footnotetext{
${ }^{53}$ ANDREAU, 2010, p. 59-60: "Les conquêtes permirent de réduire en esclavage des foules d'ennemis. Les terres des membres des deux grands ordres, les sénateurs et les chevaliers, qui, jusqu'à la fin de la République, étaient avant tout situées en Italie centrale et méridionale, et en particulier dans le Latium et en Campanie, furent donc à cette époque, et pour une très large part, cultivées par des esclaves - ce qui a stimulé le commerce des esclaves. Ces fortes évolutions ont conduit, au II ${ }^{\mathrm{e}}$ siècle av. J.-C., à des transformations de l'agriculture, qui s'est orientée vers quelques cultures destinées à la commercialisation, et notamment vers l'arboriculture (vigne et olivier). Le traité de Caton l'Ancien (De Agricultura) est une sorte de symbole de cette transformation, que certains qualifient même de révolution". - "As conquistas tornaram possível escravizar multidões de inimigos. As terras dos membros das duas grandes ordens, os senadores e os cavaleiros, que, até o final da República, estavam principalmente situadas no centro e sul da Itália, em particular no Lácio e na Campânia, foram, portanto, nessa época e em enorme parte, cultivadas por escravos - o que estimulou o comércio de cativos. Essas significativas evoluções levaram, no segundo século II a.C., a transformações da agricultura, que se voltou para certos cultivos destinados à comercialização, em particular para a arboricultura (vinha e oliveira). O tratado de Catão, o Velho (De Agricultura), é uma espécie de símbolo dessa transformação, que alguns qualificam, até, como "revolução"'.

${ }^{54}$ THIBODEAU, 2011, p. 45: "To sum up, then, the uilicus could on various grounds challenge the landowner for the title of agricola: he was the person in charge of the estate, he was the person performing manual labour on it, he possessed the most practical knowledge of the farm, and it was for him that the handbooks' advice was destined.
} 
familias livre e responsável, no início da república romana, por lavrar suas próprias terras, contando com o auxílio da prole e de poucos cativos. ${ }^{55}$ Ocorre, na verdade, que o ideal de frugalidade, coragem e justeza moral associável ao agricola acabou por cristalizar-se no imaginário dos latinos como espécie de modelo de conduta a ser, de algum modo, "mantido" em tempos subsequentes. Havia mesmo anedotas que ligavam personagens heroicas da história de Roma a semelhante estilo de vida, como aquela evocativa do gesto do general Lúcio Quíncio Cincinato, que teria sido diretamente chamado do trabalho de arar o solo em sua modesta propriedade agrícola para assumir a ditadura do Estado, durante uma crise - ataques belicosos dos équos e volscos - ocorrida no ano de 458 a.C. (TITO LÍVIO, Ab Vrbe condita III, 26 apud ROBERT, 1985, p. 85).

Mesmo quando, decerto, não trabalhavam mais as terras com suas mãos, ${ }^{56}$ por outro lado, muitos membros das elites socioeconômicas de Roma continuaram a apreciar os vínculos tradicionais de suas famílias com a imagem idealizada do agricola. No proêmio de De agri cultura, por sinal, Catão lisonjeia o público original de seu pequeno tratado, o

If a landowner was going to pretend to be a farmer, the figure who was in so many regards already playing that role would first have to be eliminated". - "Resumindo, então, o uilicus poderia, por vários motivos, desafiar o proprietário de terras pelo título de agricola: ele era o responsável pela propriedade, ele era a pessoa que realizava o trabalho manual nela, detinha o conhecimento mais prático da fazenda, e era para ele que o aconselhamento dos manuais se destinava. Se um proprietário de terras fosse fazer-se de fazendeiro, a figura que já estava, em tantos aspectos, desempenhando esse papel teria, primeiro, de ser eliminada".

${ }_{55}$ ROBERT, 1985, p. 85: "Le citoyen romain est un petit propriétaire qui ne possède q'un ou deux esclaves, bien suffisants pour cultiver une terre qui n'est jamais immense. Il cultive ses biens en famille. Certes, il va à la guerre de mars à octobre, mais revient ensuite chez lui pour gérer son bien". - "O cidadão romano é um pequeno proprietário que tem apenas um ou dois escravos, o suficiente para cultivar uma terra que nunca é imensa. Ele cultiva sua propriedade em família. Certamente, ele vai para a guerra de março a outubro, mas depois retorna para casa a fim de administrar sua propriedade". ${ }^{56}$ THIBODEAU, 2011, p. 45: "Rather than perform farm work, what the dominus generally did on his estate was make inspections and give commands". - "Em vez de realizar trabalho agrícola, o que o dominus geralmente fazia em sua propriedade era proceder a inspeções e dar comandos". 
dos ricos proprietários de terras dedicadas à arboricultura comercial, ${ }^{57}$ afirmando-lhe que os "ancestrais do povo de Roma" (maiores populi Romani), ao elogiarem um homem bom, "elogiavam assim: um bom agricultor e um bom fazendeiro" (ita laudabant, bonum agricolam bonumque colonum). Lembremos ainda de que, do ponto de vista prático, a ordem senatorial foi amiúde vinculada, em termos de sua maneira essencial de ganho econômico, à posse e exploração agrícola das melhores terras itálicas, tendo havido inclusive uma lei que vetava a posse de navios além de certa tonelagem pelos senadores, como forma de evitar que se "desviassem" dos estáveis e "sãos" afazeres agrícolas para as aventuras da vida de mercadores (GRIMAL, 1992, p. 141).

O efeito resultante da eliminação do uilicus dos horizontes instrutivos do magister corresponde a que o leitor, que se vincula ao papel do discipulus/“aluno" na poesia didática, passa a ser endereçado em segunda pessoa como único destinatário dos preceitos contidos nas Geórgicas, de modo a assumir sem intermediários as prestigiosas feições do agricola (THIBODEAU, 2011, p. 45). Isso se dá quer nas partes do poema nas quais o termo assume seu sentido original, o do pater familias a lavrar o solo com suas mãos, quer naquelas em que se tem alguma impressão de se tratar, sobretudo, de uma figura no comando, não na direta execução de tarefas braçais, em maior harmonia histórica com o perfil de muitos dos leitores citadinos da obra (THIBODEAU, 2011, p. 29-30), na Roma de Virgílio. Não obstante, notemos com Thibodeau que, para grande parte das propriedades agrícolas em operação na Itália augustana, eliminar o uilicus "não era uma opção viável no mundo real" (THIBODEAU, 2011, p. 45). ${ }^{58}$

\section{Conclusão}

O leitor confrontado com as Geórgicas de Virgílio não deve de imediato entender que divisamos, nesse texto, um simples manual de agricultura metrificado, em que os recursos tradicionalmente associáveis

\footnotetext{
57 Veja-se nota 53.

58 "[...] this was not a viable option in the real world".
} 
à poesia (versos, sons, ritmos, impressivas imagens...) venham somente sobrepor-se ou tornar mais "palatável” um camada instrutiva compacta, coerente e de todo funcional no quesito da informatividade técnica. Antes, o peculiar direcionamento que se deu, na composição da obra, para a caracterização da figura do magister - distanciado, urbano e "mero" poeta, não fazendeiro - e os sentidos advindos da frequente superficialidade expositiva, bem como da "seletividade" na abordagem, sobretudo, de assuntos capazes de serem expressivos do ponto de vista das associações semânticas que despertam, fazem pensar em um texto dotado de parâmetros distintos do intento de apenas informar e afim à constituição de uma imagem sui generis, ou não tanto "factual", da lida agrária na Itália antiga.

Nesse movimento de feitura de um mundo "recortado" sob os ditames da poesia, ainda, o relativo esmaecimento da atuação dos cativos, tão essenciais nos campos itálicos desde tempos recuados, e, em específico, a troca completa do uilicus pelo agricola na encenação da "aula", são fatores de reforço ao aspecto ficcional das imagens da ruralidade nas Geórgicas. A soma de tantos elementos a causarem ruído no fluxo comunicativo "prático" do poema, enfim, há de ter justificado que, desde a Antiguidade, os juízos de muitos críticos tenham pendido para a consideração desse texto como complexo produto da poesia, no sentido aqui proposto. ${ }^{59}$

\section{Agradecimento}

Agradeço ao prof. Olimar Flores Júnior (FALE-UFMG) pelo convite que motivou a escrita deste artigo.

${ }^{59}$ SÊNECA, Epistulae Morales ad Lucilium LXXXVI, 15: Vt ait Vergilius noster, qui non quid uerissime, sed quid decentissime diceretur aspexit, nec agricolas docere uoluit, sed legentes delectare. - "Como fala nosso Virgílio, que não olhou o que dissesse do modo mais verdadeiro, mas do modo mais especioso, nem quis ensinar aos agricultores, mas deleitar quem o lesse". 


\section{Referências}

ANDREAU, J. L'économie du monde romain. Paris: Ellipses, 2010.

BORNECQUE, H.; MORNET, D. Roma e os romanos. Tradução de A. D. Lima. São Paulo: EPU, 2002.

CATÃO. Da agricultura. Tradução, introdução e notas por M. Trevizam. Campinas: Unicamp, 2016.

DALZELL, A. The Criticism of Didactic Poetry: Essays on Lucretius, Virgil and Ovid. Toronto: University of Toronto Press, 1996.

GALE, M. Virgil on the Nature of Things: The Georgics, Lucretius and the Didactic Tradition. Cambridge: Cambridge University Press, 2000.

GRIMAL, P. Dictionnaire de la mythologie grecque et romaine. Paris: Presses Universitaires de France, 1963.

GRIMAL, P. Virgílio, ou o segundo nascimento de Roma. Tradução de I. C. Benedetti. São Paulo: Martins Fontes, 1992.

HESÍODO. Os trabalhos e os dias. Tradução de M. C. N. Lafer. São Paulo: Iluminuras, 2008.

MORGAN, L. Patterns of redemption in Virgil's Georgics. Cambridge: Cambridge University Press, 1999.

NELSON, S. God and the Land: The Metaphysics of Farming in Hesiod and Vergil. New York/Oxford: Oxford University Press, 1998.

OTIS, B. Virgil: A Study in Civilized Poetry. Norman: Oklahoma University Press, 1995.

ROBERT, J.-N. La vie à la campagne dans l'Antiquité romaine. Paris: Les Belles Lettres, 1985.

SENECA. Ad Lucilium epistulae morales. With an English translation by R. Gummere. Cambridge, Mass./London: Harvard University Press/ Heinemann, 1917-1925. v. I-III.

THIBODEAU, P. Playing the Farmer: Representations of Rural Life in Vergil's Georgics. Berkeley/Los Angeles/London: University of California Press, 2011. 
TREVIZAM, M. Mal e violência nas Geórgicas de Virgílio. In: OLIVEIRA, F.; SILVA, M. F.; BARBOSA, T. V. R. (Org.). Violência e transgressão: uma trajetória da humanidade. Coimbra: Imprensa da Universidade de Coimbra; São Paulo: Annablume, 2014. p. 189-230.

UREÑA PRIETO, M. H. T. Dicionário de literatura grega. Lisboa: Verbo, 2001.

VARRÃO. Das coisas do campo. Tradução de M. Trevizam. Campinas: Unicamp, 2012.

VASCONCELLOS, P. S. Épica I. Campinas: Unicamp, 2014.

VIRGIL. Georgics: volume 1 - books I-II. Edited by R. F. Thomas. Cambridge: Cambridge University Press, 1994.

VIRGILE. Géorgiques. Traduit par E. de Saint-Denis. Paris: Les Belles Lettres, 1998.

VIRGíliO. Eneida. Tradução de C. A. Nunes, organização de J. A. Oliva Neto. São Paulo: Editora 34, 2014.

VIRGÍLIO. Geórgicas I. Tradução de M. Trevizam e A. F. de Castilho. Belo Horizonte: UFMG, 2013.

VOLK, K. The Poetics of Latin Didactic: Lucretius, Vergil, Ovid. Oxford: Oxford University Press, 2002.

WEEDA, L. Vergil's Political Commentary in the Eclogues, Georgics and Aeneid. Berlin/New York: De Gruyter, 2015.

WILKINSON, L. P. The Georgics of Virgil: a Critical Survey. Norman: Oklahoma University Press, 1997.

Recebido em: 20 de setembro de 2018. Aprovado em: 28 de novembro de 2018. 